\title{
SÓCRATES E A IRONIA SEGUNDO VLASTOS
}

\author{
Admar Costa* * Universidade \\ Federal Rural \\ do Rio de Janeiro.
}

Obra de finado.

Escrevi-a com a pena da galhofa e a tinta da melancolia, e não é difícil antever o que poderá sair desse conúbio.

Machado de Assis. Memórias Póstumas de Brás Cubas.

RESUMO: Qual o sentido da ironia de Sócrates? Em torno dessa questão central para compreendermos Sócrates - o personagem mais famoso da História da Filosofia - Vlastos empreende um grande esforço para ressignificar positivamente o termo ironia e defender Sócrates das acusações de um Trasímaco ou de um Cálicles. A base da defesa é dizer que Sócrates, mesmo quando se vale de expediente moralmente condenável, o faz em nome de um fim nobre, em vista de descobrir como devemos agir para que tenhamos uma vida boa e justa. Com argumentos fortes e frágeis, Vlastos é responsável por motivar uma série de artigos sobre o tema, o que torna sua tese algo central para os estudiosos de Platão. Com o objetivo de entrar nessa discussão, esse trabalho analisa e confronta o papel da ironia socrática.

PALAVRAS-CHAVE: Vlastos; Sócrates; ironia.

SOCRATES AND IRONY ACCORDING TO VLASTOS

\begin{abstract}
What is the meaning of Socrates' irony? Around this central issue concerning the understanding of Socrates - the most famous character in the History of Philosophy - Vlastos undertakes a major effort to positively reframe the term irony and defend Socrates from the accusations of a Thrasymachus or a Callicles. The defense relies on the idea that when Socrates makes use of morally reproachable procedures, he does so on behalf of a noble end, in order to figure out how we should act to have a good and righteous life. With strong and weak arguments, Vlastos therefore motivates a series of articles on the subject, which makes his thesis central to Plato's scholarship. In order to take part in the debate, this paper aims to provide analysis of the role of Socratic irony.
\end{abstract}

KEYWORDS: Vlastos; Socrates; irony. 
V lastos, no primeiro capítulo do livro intitulado Socrates, Ironist and Moral Philosopher, ${ }^{1}$ explora, de modo exemplar, o sentido do termo ironia, em especial no que tange à identificação do famoso estilo eternizado por Sócrates. Responsável pela profunda transformação sofrida pelo vocábulo grego éı muda a palavra ao teorizar sobre ela, mas cria algo novo para ela exprimir: uma nova forma de vida que em si mesma era percebida como a própria encarnação da ironia, segundo o uso contemporâneo; um uso inocente e intencional da fraude, como aquele da criança que finge que as fichas do jogo são dinheiro".

Antes de Sócrates, porém, prevaleceria a conotação negativa, encontrada, por exemplo, em Aristófanes, onde ع"ip Vestígios dessa conotação ecoam na fala de Trasímaco, no livro I da República ou, um pouco mais tarde, em Teofrasto, que inicia o seu livro Caracteres, ${ }^{4}$ explicando o significado de


palavra ou em ação, e destina-se a fazer as coisas aparecerem diferentemente (ou parecerem diferentes) do que realmente são"; aquele que é identificado como irônico é percebido como “odioso, enganador, venenoso e perito na autocamuflagem”. Como ao longo das duas páginas dedicadas ao tema da ironia o leitor de Teofrasto não encontra qualquer emprego positivo do termo, os entusiastas de Sócrates poderiam rejeitar, cabalmente, que o famoso filósofo fosse descrito como ironista, o que inviabilizaria os esforços de Vlastos em mostrar o contrário.

Todavia, se analisamos a estratégia da "apologia socrática" feita por Vlastos, logo percebemos que o sentido negativo que marca a "ironia" na Antiguidade é rapidamente esvaziado e convertido em seu contrário, o que torna a pergunta "quem foi Sócrates?” menos polêmica do que poderia parecer, pois o leitor de Vlastos pode facilmente antecipar a resposta alcançada, antes mesmo de percorrer toda a exposição. ${ }^{5}$ Metodologicamente, Vlastos principia com a descoberta e recuperação de uma nuance positiva de éı e Quintiliano e, além disso, na diferenciação, elaborada a partir desses autores, ${ }^{6}$ entre ironia simples e ironia complexa. Ele defende que há dois sentidos de ironia subjacentes aos textos: no primeiro, "o que é dito não é simplesmente o que é entendido", ou seja, "tomado em sentido usual, comumente compreendido, o sentido da afirmação é simplesmente falso";

\footnotetext{
${ }^{1}$ VLASTOS, 1991.

${ }^{2}$ VLASTOS, 1991, p. 29.

${ }^{3}$ Para ilustrar os diversos sentidos do termo, Vlastos menciona Aristófanes, no qual o uso de



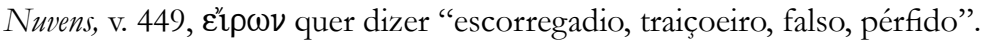

${ }^{4}$ THEOPHRASTUS, 1902. Cf. também VLASTOS, 1991, p. 24.

${ }^{5}$ Nas palavras de Vlastos, trata-se de saber se Sócrates é um "lifelong deceiver" ou um "lifelong ironist”. Cf. VLASTOS, 1991, p. 34.

"A definição de ironia apresentada por Quintiliano é "contrarium ei quod decitur intelligendum est", Institutio Oratoria, 9.22.44 e 6.2.15 e também 8.6.54. Tal concepção teria sido consolidada a partir de Cícero (De Oratore, 2.67).
} 
no segundo caso, continua ele, “o que é dito é e não é aquilo que se entende: a superfície contém um sentido que pode ser verdadeiro em um caso e falso em outro".

Como tal distinção não se manifesta claramente, por exemplo, no Sócrates de Xenofonte, ${ }^{8}$ Vlastos é obrigado a circunscrever sua interpretação ao Sócrates de Platão para, logo em seguida, dividi-lo em dois. Sócrates $(\mathrm{M})$ - dos diálogos de maturidade - diferenciase do Sócrates (E), dos diálogos de juventude. A premissa básica é a de que o Sócrates dos primeiros diálogos platônicos é mais fiel ao histórico, em contraste com aquele dos diálogos da maturidade e da velhice. Por sua vez, a ironia complexa é um traço marcante dos diálogos de juventude e, portanto, do Sócrates histórico.

Em defesa dessa tese, desenvolvida de modo detalhado no capítulo "Sócrates contra Sócrates em Platão" (VLASTOS, 1991), Vlastos esclarece que "Sócrates E” é um filósofo que se ocupa somente de questões morais, ao passo que "Sócrates M" tem uma teoria das Formas e uma concepção de alma que "Sócrates E” não tem. Quem aceita esse esquema aceita também que Sócrates jamais engana ou dissimula, quando o que está em jogo é a preocupação com o tipo de vida que se deve ter e que, sobre questões morais, ele não permite que haja qualquer engano voluntário, seja de outrem, seja de si mesmo.

Ora, a dificuldade de fechar esse esquema interpretativo é visível e foi apontada por vários autores como veremos na conclusão. Apesar disso, o problema em si pode ser relevante


de Trasímaco ou na confissão de Alcibíades. Em primeiro lugar, como afirma Vlastos, é preciso atentar para o fato de que o significado do termo encontrado atualmente no inglês ${ }^{9}$ - o que é igualmente válido para o português e para o francês - teria sofrido a influência do sentido tardio de ironia, consolidado a partir de Cícero e Quintiliano. Por esse motivo, o dicionário eletrônico Houaiss, na nossa língua, indica que "ironia é uma figura por meio da qual se diz o contrário do que se quer dar a entender". Para o dicionário Aurélio, o significado é parecido: "Modo de exprimir-se que consiste em dizer o contrário daquilo que se está pensando ou sentindo". Conclusão: não há correspondência exata entre ép os termos equivalentes nas línguas mencionadas e, consequentemente, usar o mesmo termo para traduzir as duas passagens platônicas pode acarretar mais confusão que elucidação. Se o último argumento é válido, também o será aquele que questiona a escolha de Vlastos pelo sentido tardio de ironia para decifrar o Sócrates platônico. Essa decisão - argumenta Melissa

\footnotetext{
7 "Simple irony: what is said just isn't what is meant: taken in its ordinary, commonly understood, sense the statement is simply false. Complex irony: what is said both is and isn't what is meant: its surface content is meant to be true in one sense, false another". Cf. VLASTOS, 1991, p. 32.

8 "In the first place, the ironies Xenophon puts into the portrait have little doctrinal significance. They contribute nothing to the elucidation of Socrates' philosophy because Xenophon systematically ignores those very features of it which Socrates wants to be understood as "complex ironies". VLASTOS, 1991, p. 31.

${ }^{9} \mathrm{Em}$ inglês temos que “irony is the expression of one's meaning by saying the direct opposite of what one is thinking but using tone of voice to indicate one's real meaning". Advanced Learner's Dictionary, 1995.
} 
Lane $^{10}$ - expõe a preferência por Aristóteles em detrimento de Aristófanes e dificilmente poderia ser justifica através da obra de Platão na qual, segundo a autora, prevalece o sentido aristofânico de દ̇ $\rho \omega v \varepsilon i ́ \alpha$ como ação de "ocultar" (to conceal) algo, o que pode se dar por meio do ato de "fingir" (to feign).

Para Vlastos, porém, esse sentido não pode ser generalizado em Platão, restringindose à fala de Trasímaco, quando este menciona a "habitual trapaça" (shamming) ou "fingimento" (feigning) de Sócrates na República (337a). As palavras são duras e acompanhadas de outras não menos provocadoras. Na casa de Céfalo, o gigante da Calcedônia acusa Sócrates de perseguir

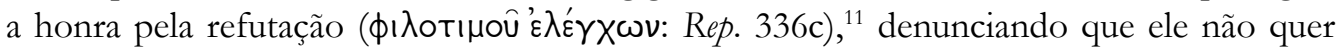
saber, verdadeiramente, o que é a justiça, e afirmando que o que caracteriza o costume ou o fazer de Sócrates é pedir uma resposta para depois refutá-la (Rep. 337e), e que apenas nisso consistiria o seu saber. Ao fazer isso, Sócrates protege dos outros a sua própria ignorância, no que ele é duplamente bem sucedido: ele não revela sua ignorância e ainda dissemina a impressão de que sabe mais que aquele que viu sua resposta refutada. Se essa interpretação da fala de Trasímaco é válida, Vlastos acerta quando percebe o eco do sentido da ironia de Aristófanes na fala de Trasímaco, mas, de acordo com Melissa Lane, ${ }^{12}$ erra ao entender que o sofista denuncia a intenção de Sócrates como a de trapacear e não, simplesmente, como a de esconder que ignora o que seja a justiça. A euforia de Trasímaco favoreceria a tese de Lane, pois, ao mostrar-se ansioso por apresentar sua própria definição de justiça, Trasímaco crê que ela é realmente imbatível e que ele saberia algo que Sócrates não sabe. O diálogo precedente, entre Sócrates e Polemarco, pode ter fortalecido essa convicção, tornando a ocasião mais do que propícia para Trasímaco vencer Sócrates, um objetivo que ele mesmo confessa ao dizer que o importante, em uma discussão, não é o que realmente pensamos, mas sim não

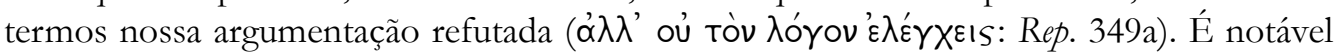
ainda que esse Trasímaco incontido seja chamado de amigo, por Sócrates, ao longo do livro $\mathrm{V}$ e que lá, diferentemente daqui, ele se comporte como alguém realmente interessado em discutir os grandes assuntos que tocam a existência humana e podem torná-la mais feliz. A que se deve tal mudança e por que Trasímaco se deixou convencer da dificuldade do tema

\footnotetext{
${ }^{10}$ Em referência à tradição latina consagrada por Cicero e Quintiliano e à época mais recente, com Schlegel, Hegel, Kierkegaard e Nietzsche, Lane afirma: "This later tradition has a life of its own and must be understood to stem not from Plato but from Aristotle, who is shown below to have made eirôneia mean 'irony' for his own rhetorical purposes rather than in consonance with any prior ascriptions of it to Socrates. The concept of 'Socratic irony' has no basis in Plato's use of eirôneia with respect to Socrates". (LANE, 2006, p. 49-84).

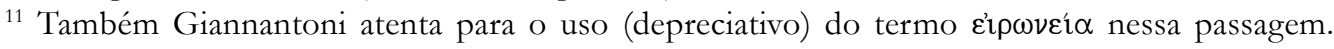
Cf. GIANNANTONI, 1993, p. 56.

${ }^{12}$ Sobre a interpretação de Vlastos, afirma Lane: "But he is wrong in implying that what Thrasymachus charges Socrates with is the attempted concealment of knowledge. The charge is rather the attempted concealment of ignorance, or better, of a feared inadequacy of any attempt to give a definition". LANE, 2006, v. XXXI, p. 70.
} 
e, como os demais, abandonou a erística em nome da dialética, são assuntos que fogem ao escopo desse trabalho.

Por ora, é preciso analisar a fala de Alcibíades no Banquete (216e; 218d), na qual o termo ironia exerce grande importância. Alcibíades parece estar tão convicto do amor de Sócrates que, em nome disso, se expõe desmedidamente ao declarar-se apaixonado e confessar todas as suas frustradas estratégias de conquista. Por esse motivo, quando ele descobre que seu amor não é correspondido, sente-se enganado e traído. O curioso é que toda a clarividência de Alcibíades parece brotar de sua embriaguez ou, ao contrário, como sugere Sócrates, apenas do ciúme causado por Agatão. Cego pelo ciúme ou pelo vinho, ele enxerga que Sócrates já havia feito o mesmo com outros rapazes, Cármides e Eutidemo, e adverte Agatão, a vítima da hora. E o que faz Sócrates? Engana ( $\varepsilon \xi \alpha \pi \alpha \tau \omega \hat{v}$ : 222b) ao declarar-se amante e esconder que é, na verdade, o amado. O meio encontrado para isso é o discurso, como confessa Alcibíades: "Quando o escuto, bate-me o coração muito mais violentamente do que aos coribantes em suas danças sagradas, e lágrimas me escorrem sob o efeito de seus discursos" (215e).

Sob a possessão erótica, Alcibíades descreve as forças que atuam sobre ele, remetendo-nos ao vocabulário poético que, de modo recorrente, associa Eros e Afrodite ao poder de enganar e perturbar o juízo dos amantes, como no famoso verso em que Homero descreve o mágico acessório de Afrodite, emprestado a Hera, para roubar o juízo de Zeus. ${ }^{13}$ Com a visão alterada, Alcibíades vem revelar-nos que o feioso Sócrates, tal como

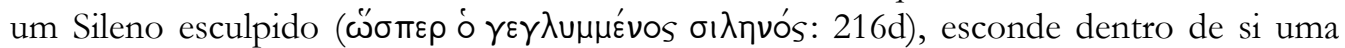
grande temperança (sophrosýne) em nome da qual ele despreza riquezas, títulos, honras e beleza física. Tendo descoberto essa maravilha que Sócrates esconde, ele se vê dominado pelas palavras do mestre, como Odisseu diante das Sereias. Toda a magia da fala, todo o poder do discurso, ressoa pelas palavras de Sócrates, e o que se percebe e se recebe é seu efeito: um encantamento que é tanto mais forte quanto menos se deixa decifrar.

E o que haveria para ser decifrado, se o próprio Sócrates adverte-nos: "Não


sobre Alcibíades como aquela velha astúcia com que "Ninguém" tirou a visão do gigante Polifemo. Alcibíades sabe apenas que Sócrates esconde algo maravilhoso, mas não sabe o que é esse "algo", nem se ele pode acessá-lo. Resta-lhe, então, trocar tudo que tem - sua beleza, juventude e prestígio - por aquilo que julga estar guardado em Sócrates e que foi nomeado genericamente por temperança. Mas o fundamental aqui é o contexto erótico e tudo que ele possibilita em termos de inquietação dos amantes diante da recusa do amado Sócrates em oferecer qualquer satisfação àquele que é só falta, e nisso consiste seu enigma: instaurar a falta e o vazio e negar, de todo modo, que ele ou qualquer outra coisa pode preenchê-lo. Com essa atitude, a porta à filosofia está aberta e ela certamente se fecharia caso a falta se convertesse em repleção.

${ }^{13}$ HOMERO, Ilíada, XIV, v. 214-217. 
Como resume Vlastos, "Nós podemos entender o Eros de Sócrates como ironia complexa", já que "Sócrates ama e não ama todos os belos jovens". ${ }^{14}$ Interpretação próxima à de Kierkegaard quando observa que a ironia atua "enquanto negatividade infinita absoluta", 15 e desse modo move o motor da busca, tal qual o amor, ao instaurar o desejo em relação ao objeto amado. A ironia e o amor, portanto, impõem o nada ou o negativo, fazendo-nos flutuar entre a falta e a repleção. Moradora da contradição, a ironia não se revela nunca e jamais pode ser aprisionada, apesar de todos os esforços empreendidos nessa direção; é exatamente isso o que faz de Sócrates um ser irresistível que "passou sua vida constantemente entre a caricatura e o ideal, e assim também continua ele entre ambos após a morte". ${ }^{16}$ Enfim, Trasímaco e Alcibíades, quando utilizam Éı direção, a saber, que há algo de oculto na fala ou modo de ser de Sócrates e que isso acaba de ser percebido e revelado por eles: o primeiro crê que o que se esconde é a ignorância, ao passo que o segundo declara que é o ato de mostrar-se amante quando, de fato, é amado; é a partir desse jogo de mostrar e ocultar que Vlastos nos propõe a distinção entre ironia simples e complexa.

\section{IRONIA COMPLEXA}

Sócrates ama e não ama; Sócrates nega, mas admite conhecer; nega, mas admite a arte de ensinar a virtude; nega, mas admite fazer política. ${ }^{17}$ É desse modo que Vlastos adiciona a Apologia e o Laques à discussão, e explicita a prática irônica de Sócrates através do jogo mediado pela contradição negar-admitir, não simplesmente no nível verbal, mas como uma nova forma de vida em que a ironia estivesse encarnada. Se a ironia é um modo de exprimirse que consiste em dizer o contrário daquilo que se está pensando ou sentindo, como já se mencionou, ela pode ser facilmente confundida com a ação de enganar, fingir ou dissimular. O que certamente demandaria algum tipo de justificativa capaz de livrar o praticante dessa arte de acusações morais. Essa discussão, enfrentada corajosamente por Vlastos, está em constante diálogo com Charles Kahn, ${ }^{18}$ para quem Sócrates faz uso da "dialectical trickery" para contrapor o argumento de Polo, no Górgias (474c-475c). A permissão para ludibriar, quando se está perseguindo fins nobres, não é admitida por Vlastos, que apresenta a sua própria compreensão do tema, a saber, a de que Sócrates não engana quando argumenta de modo sério e argumenta de modo sério quando pesquisa como se deve viver ${ }^{19}$ e quando apresenta sua pesquisa como resultado da obediência ao deus. Outro argumento apresentado, e não menos importante, diz respeito à tarefa que o próprio Sócrates se impõe na Apologia

\footnotetext{
${ }^{14}$ VLASTOS, 1991, p. 41.

${ }^{15}$ KIERKEGAARD, 1991, p. 35.

${ }^{16}$ KIERKEGAARD, 1991, p. 27.

${ }^{17}$ Para Vlastos: "i. Socrates disavows, yet avows, knowledge; ii. He disavows, yet avows, the art of teaching virtue; iii. He disavows, yet avows, doing politics”. (cf. VLASTOS, 1991, p. 237).

${ }^{18} \mathrm{KAHN}, 1983$, p. 83.

${ }^{19}$ VLASTOS, 1991, p. 134.
} 
(28e): "examinar a si mesmo e aos outros". O exame dos outros parece autorizar um tipo de argumentação desafiadora, capaz de testar verdadeiramente o interlocutor, propondo-lhe enigmas e dificuldades estratégicas, como no caso do Cármides (166c-d), em que Sócrates finge saber a receita para a cura da dor de cabeça do personagem que dá nome ao diálogo, com a finalidade de atraí-lo para uma conversa e avaliar seus conhecimentos. Além disso, há os casos em que o interesse de Sócrates é simplesmente testar a opinião que o interlocutor apresenta para descobrir, primeiro, se ela é própria ou emprestada de outro sábio, depois, quais argumentos ele é capaz de formular para defendê-la, como é o caso do Teeteto, no diálogo homônimo (151e-152a), quando nos apresenta a definição, ouvida do mestre Protágoras, de que conhecimento é sensação. Nesses dois casos, Vlastos parece admitir os estratagemas de Sócrates como um meio para se atingir ou se provar algo, mas em nenhum caso - diz ele $^{20}$ - o engano do interlocutor poderia influir ou contribuir para o engano de si mesmo ou ainda para o engano involuntário. ${ }^{21}$

Em linhas gerais, portanto, a função da ironia ou da refutação praticadas por Sócrates não parece se confundir com a simples intenção de enganar o interlocutor. Se isso ocorre, o motivo pode estar misturado com a própria forma do diálogo e com a concepção de filosofia contida nele. Em outras palavras, pode-se enganar com algumas palavras fora de contexto, não com a obra mesma e sua função; o contexto dramático do diálogo diz muito a respeito de seu significado e ambas as análises, do contexto e do discurso, devem ser feitas de modo meticuloso pelo leitor e isso, a meu ver, é parte da estratégia platônica para disseminar o ensinamento filosófico como exercício que envolve ação e discurso. Essa forma, que parece insistentemente aludir a algo mais, que extrapola o imediatamente entendido, confere às falas e aos próprios personagens uma dimensão grandiosa, e isso é, em nossa opinião, antes a causa que o efeito da ironia. $\mathrm{Na}$ atmosfera platônica, não só a ironia torna-se complexa, mas também a refutação e toda a ação que é encarnada por seus personagens. Se o sentido tardio do termo ironia parece combinar com a forma do diálogo platônico ao fazer-nos mais atentos a cada fala e gesto de seus personagens, vejamos que proveito ela nos traria.

\section{A FUNÇÃo DA IRONIA}

O Sócrates do Fedro (269a), depois de se confessar inteiramente apaixonado pela dialética, precisa prestar contas a Fedro, acerca das sutilezas da arte retórica

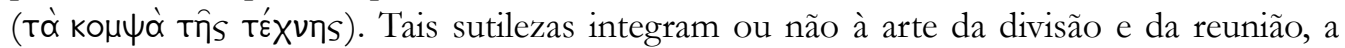
dialética? Se considerarmos que a ação de falar bem implica tais sutilezas e que isso torna a fala mais eficaz no alcance de seus objetivos, então, aquilo que parecia externo transformase em constitutivo. A ironia socrática parece ser um exemplo dessa combinação de estilo e conteúdo, cuja função é mostrar quem é Sócrates e qual é a sua filosofia, isto é, como ele age e como ele pensa. Caberá, no entanto, ao interlocutor ou ao leitor, a justa percepção

\footnotetext{
${ }^{20}$ VLASTOS, 1991, p. 135.

${ }^{21}$ Nos diálogos República (451a) e Fedro (262a), por exemplo, formula-se a tese de que não se deve enganar ou se deixar enganar de modo involuntário.
} 
dessa combinação, pois o risco é que as sutilezas encubram o conteúdo ou vice-versa. Logo, é preciso compreender o pensamento de Sócrates de Platão para avaliarmos se suas atitudes estão ou não de acordo.

A primeira coisa a entender é que Sócrates encarna um paradoxo e que esse é parte da estratégia platônica - ou seria socrática? - para discutir filosofia. Portanto, ele funciona positiva e tecnicamente e, como paradoxo, não deve ser reduzido ou desfeito. Nessa perspectiva, a tese da ironia complexa parece permitir que Vlastos se mostre persuadido de que, em Sócrates, a convicção de não saber convive com a convicção de possuir a verdade. ${ }^{22}$ Ao fundo, parecem ressoar as palavras de Schleiermacher: "faz parte do interior e da essência da forma platônica tudo aquilo que resulta da intenção de obrigar a alma do leitor à produção de ideias próprias." ${ }^{23}$

Com efeito, para trazer o leitor para dentro do texto e obrigá-lo a se posicionar, parece absolutamente necessário que o diálogo - sempre aberto - não se converta jamais em doutrina ou tratado e que isso não seja um fim apenas almejado, mas um meio, que se concretiza a partir de uma tensão, às vezes tênue, entre conteúdo filosófico e forma dialógica, entre Sócrates e seus interlocutores.

Longe, portanto, da imagem do mestre que soluciona problemas, a figura de Sócrates invoca diálogo, debate, combate, jogo. No jogo, se revela outra sutileza inerente à ironia e cuja função é livrar Sócrates da condenação de levar o engano a sério. Com ele, em sintonia com Colli, que afirmou que "o enigma aparece como o fundo tenebroso e a matriz da dialética," 24 poderíamos sugerir que, com Sócrates, o próprio homem-personagem torna-se enigma, isto é, que o próprio homem parece valer-se da possibilidade - descoberta na linguagem - de atar e desatar fala e pensamento até o ponto em que a fala, de modo intencional, dissimule o pensamento de Sócrates em nome do pensamento daquele que não é Sócrates, pois já não é o saber do próprio Sócrates que está em questão, mas um outro saber, gestado em outro ventre, e que ele deve ajudar a trazer à luz, tal como sua mãe parteira fazia.

Porém, se o próprio homem se converte em enigma, é preciso perguntar-nos a causa e o objetivo disso. Logo, quando Sócrates alega não saber, não é que ele não saiba. O que está em jogo é que o seu saber - fruto da contínua busca por decifrar a si mesmo (Fedro, 229e) - de nada adianta ao seu interlocutor, porque ele não pode ser transplantado.

Para Allen, é justamente a suposição de que todos os homens possuem o autoconhecimento, ${ }^{25}$ ainda que vagamente, que justifica o fato de a ironia ser a característica tão marcante do personagem de Sócrates. Ainda segundo Allen, quando escreve sobre o paradoxo socrático, devemos compreender o conhecimento da virtude, por exemplo, como um "saber como" e não como um "saber o que". Mais uma vez isso quer dizer que não é possível saber o que é a virtude sem ser virtuoso, do mesmo modo que aquele que sabe

\footnotetext{
${ }^{22}$ Cf. GIANNANTONI, 1993, p. 55.

${ }^{23}$ SCHLEIERMACHER, 2002, p. 66

${ }^{24}$ COLLI, 1988, p. 66.

${ }^{25}$ ALLEN, 1960, p. 260-261.
} 
"como" ser virtuoso é virtuoso. ${ }^{26}$ Essa perspectiva, se não explica suficientemente por que Sócrates é irônico, ao menos liberta a ironia do plano do julgamento moral, pois se todos os homens devem praticar o autoconhecimento a fim de aperfeiçoarem a si mesmo e alcançar para si o melhor gênero de vida possível, Sócrates, que descobriu que tal conhecimento é inerente a uma prática de vida, a um ethos, que se caracteriza pela constante busca, pode e deve acentuar o efeito retórico da ironia sobre seus interlocutores para manifestar o incômodo distanciamento que se observa cotidianamente entre "saber como" e "saber o que". Quando afirma não saber o que é a virtude, Sócrates parece oferecer a sua própria vida como prova de que sabe sim, mas os interlocutores não percebem. Quando esse é o caso, a ironia parece ser percebida de modo apenas negativo, isto é, como ironia simples e não complexa. E o que faz Sócrates quando isso acontece? Ele continua seguindo o deus Apolo que, como sugere o fragmento 93 de Heráclito, não diz, só assinala. Em outras palavras, ele não se comove e não procura facilitar nada além da conta, pois, como afirma Szaif sobre o contexto da República, “até mesmo no caso de uma 'Forma' que possa ser analisada e, então, definida, parece que somente esta articulação proposicional é, de algum modo, secundária à familiaridade com a 'Forma' mesma, que não pode ser estabelecida simplesmente pelo aprendizado de uma fórmula que a define. Se assim fosse, a instrução filosófica seria fácil, e poderia consistir em memorizar fórmulas de definições. Esta definitivamente não é a posição de Platão". ${ }^{27}$

Formulação semelhante à de Allen e, por tabela, à de Szaif, Vlastos apresenta sobre o ensino. A tese é de que o verdadeiro Sócrates diz não ensinar, porque compreende que ensino não é transferir conhecimento. Sócrates diz não conhecer, porque entende que o conhecimento depende de argumentos justificados e, nesse campo, no que se refere ao método do argumento da refutação (elenchos), existem muitas proposições que ele tem a pretensão de saber. ${ }^{28}$ Voltando a Allen, sobre a concepção de conhecimento, ele afirma que Platão distingue o conhecimento da crença e o define por sua capacidade de prestar contas e por seu campo de objetos". ${ }^{29}$ Além de poder justificar, é necessário, portanto, o conviver,


- Rep. 490b) daquilo que se quer conhecer.

Por outro lado, um traço não menos importante relacionado à ironia socrática é justamente a atopia, ${ }^{30}$ que parece reforçar e justificar a primeira, à medida que mostra que a filosofia não tem lugar na cidade, pois o filósofo, como denuncia Cálicles no Górgias (486c2-3), cochicha pelos cantos com uma meia dúzia de jovens e não se vê jamais inserido no jogo das grandes decisões concernentes à cidade. Nessa perspectiva, a função da ironia

\footnotetext{
${ }^{26}$ Cf. ALLEN, 1960, p 258.

${ }^{27}$ SZAIF, 2007, p. 23

${ }^{28}$ VLASTOS, 1991, p. 32.

29 "Plato distinguishes knowledge from belief and defines it by its ability to 'render an account' and by its field of objects" (ALLEN, 1960, p. 261).

30 Também para Giannantoni "a ironia e a atopia são traços fundamentais do retrato de Sócrates". Cf. GIANNANTONI, 1993, p. 57
} 
não seria muito diferente do recurso das "entrelinhas" consagrado por Strauss: um meio usado para a divulgação e para a proteção da filosofia. ${ }^{31}$

\section{À GUISA DE CONCLUSÃo}

Nesse emaranhado de soluções que redundam em novos problemas, o terreno parece fértil para críticas e discordâncias. Apesar da ligação estreita, suposta por Vlastos, entre ironia complexa e o Sócrates histórico, marcadamente o personagem dos diálogos da juventude, nenhuma ocorrência clara dessa ironia é encontrada em outras fontes socráticas. Giannantoni chega a perguntar "por que Xenofonte não caracteriza Sócrates como irônico, como faz Platão?" 32 e a resposta de Vlastos - não muito distante da oferecida por Kierkegaard - é simplesmente que Xenofonte não foi capaz de perceber esses e outros fatos sutis e importantes na filosofia socrática, ao passo que Platão não só os percebeu como os acentuou. Ao problema poder-se-ia acrescentar ainda a seguinte dúvida: será que há outro sentido para a ironia do que aquele atribuído a Sócrates por Aristófanes?

A essa pergunta, Melissa Lane responde negativamente e vai além ao defender que o sentido da ironia nas falas de Trasímaco ou de Alcibíades, apesar das diferenças de contexto, alude sempre à ação de esconder algo e não foge do sentido predominante em Aristófanes e em Platão. Se aquilo que deveria ser escondido se revela à vítima, variadas reações são suscitadas nessa, o que inclui o júbilo de não ser enganada e o júbilo de poder denunciar aos outros a própria intenção. Quem percebe a ironia, portanto, sente-se superior ao ironista e pode sentir-se mais ou menos ofendido, dependendo do contexto em jogo, daquilo que se tentou esconder e do tipo de interlocutor que descobriu tal intenção. Há, portanto, uma variação observada na recepção da ironia em diversas passagens, mas isso não implica, conclui Lane, que se possa falar em uma transformação semântica do termo produzida por Sócrates, como defende Vlastos, ou que se possa atribuir a Platão a visão de que Sócrates era irônico.

Em outro aspecto, argumenta Charles Kahn, não há diálogos socráticos, mas sim diálogos de Platão. Logo, a distinção apresentada por Vlastos entre Sócrates (M) e Sócrates (E) pareceria inverossímil, especialmente diante da interpretação de Monique Dixsaut, ${ }^{33}$ para quem Platão, todo ele, é e continua sendo socrático, e que não há qualquer ruptura - e sim metamorfose - entre os procedimentos típicos dos diálogos de juventude e de maturidade.

Por último, se a ironia não identifica o que era habitual no Sócrates histórico, nem no personagem de Platão, ao menos devemos reconhecer o papel instigante que ela desempenhou no famoso personagem da história e da tradição filosófica, desde os tempos de Aristóteles. Enquanto recurso retórico atribuído a um personagem fictício, ela foi capaz de transformar o odioso Sócrates vivo, condenado a partir de intrigas infundadas, em um

\footnotetext{
${ }^{31}$ Segundo Strauss, “a perseguição dá nascimento a uma técnica particular de escrita e, consequentemente, a um tipo particular de literatura, na qual a verdade sobre todas as questões cruciais está apresentada exclusivamente nas entrelinhas". Cf. STRAUSS,1952, p. 58.

${ }^{32}$ GIANNANTONI, 1993, p. 57

${ }^{33}$ DIXSAUT, 2001.
} 
morto apaixonante, brilhante e irresistível. É claro que se pode argumentar que Sócrates só era odioso para aqueles que não foram capazes de entender seu comportamento, mas, de um jeito ou de outro, são esses que o caluniaram e favoreceram sua condenação. Fazendo coro com essa tese, e para retomar a epígrafe que abriu este trabalho, acrescentaríamos apenas que a "galhofa" de Machado só pode harmonizar-se perfeitamente com a "melancolia" na pele de um personagem, e tanto melhor que esse personagem não seja um vivo, mas um morto, um morto em quem os paradoxos e as contradições sirvam para tornar os vivos ainda mais vivos e os diálogos com os mortos intermináveis, o que me parece ser o caso de Sócrates.

\section{REFERÊNCIAS}

ALLEN, R. E. The Socratic Paradox. Journal of the History of Ideas, University of Pennsylvania Press, v. 21, n. 2. p. 256-265, 1960.

CICERO. Orator. Translated by G. L. Hendrickson, H. M. Hubbell. Loeb Classical Library, 342. Cambridge, MA: Harvard University Press, 1939.

COLLI, G. O nascimento da Filosofia. Tradução de Federico Carotti. Campinas: Editora da Unicamp, 1988.

DIXSAUT, Monique. Métamorphoses de la dialectique dans les dialogues de Platon. Paris: Vrin, 2001.

HOMERO. L'Iliade. Texte établi et traduit par Paul Mazon. Paris: Les Belles Lettres, 1943. 3 v.

KAHN, C. Drama and dialectic in Plato's Gorgias. Oxford Studies in Ancient Philosophy, v. 1, p. 75-121, 1983.

KIERKEGAARD, S. O conceito de ironia. Petrópolis: Editora Vozes. 1991.

LANE, M. The evolution of eirôneia in classical greek texts: why socratic eirôneia is not Socratic irony. Oxford Studies in Ancient Philosophy, v. XXXI, 2006.

PLATÃO. Fedro. Tradução de Maria Isabel Santa Cruz. Buenos Aires: Editorial Losada, 2007.

PLATÃO. República. Tradução de Maria Helena da Rocha Pereira. Lisboa: Fundação Calouste Gulbenkian, 1993.

PLATO. Symposium. Edited by K. Dover. Cambridge: Cambridge University Press, 1980.

PLATON. Phèdre. Texte établi et traduit par Léon Robin. Paris: Les Belles Lettres, 1954.

QUINTILIAN. The Orator's Education. Translated by Donald Russell. Loeb Classical Library, 342. Cambridge, MA: Harvard University Press, 1939.

SCHLEIERMACHER, F. Introdução aos diálogos de Platão. Tradução de Georg Otte. Belo Horizonte: UFMG, 2002.

STRAUSS, L. Persecution and the Art of Writing. London: University of Chicago Press, 1952. 
SZAIF, J. Doxa and Episteme as Modes of Acquaintance in Republic V. Les Etudes Platoniciennes, Paris: Les Belles Lettres, 2007. v. IV, p. 253-272.

THEOPHRASTUS. The Caracters of Theophrastus. A translation, with introduction by Charles E. Bennett and William A. Hammond. New York-London-Bombay: Longmans, Green, and Co., 1902.

VLASTOS, G. Socrates, ironist and moralphilosopher. Ithaca/New York: Cornell University Press, 1991. (Col. Cornell Studies in Classical Philosophy, v. 50.) 